\title{
Pengaruh Heat-Moisture Treatment dan Penambahan Natrium Tripolifosfat terhadap Kualitas Mi instan dari Pati Ubi Jalar (Ipomoea batatas (L) Lam)
}

\author{
Effect of Heat-Moisture Treatment and Sodium Tripoliphosphate on the Quality of \\ Instant Noodles from Sweet Potato Starch (Ipomoea batatas (L) Lam)
}

\author{
Chatarina Lilis Suryani \\ Program Studi Teknologi Hasil Pertanian, Fakultas Teknologi Pertanian \\ Universitas Wangsa Manggala, Jl. Wates Km 10 Yogyakarta 55753 \\ Telp. (0274) 798212 Fax(0274) 798213, E-mail: Chlilis05@yahoo.com
}

\begin{abstract}
The objective of the present study was to evaluate the effect of heat-moisture treatment (HMT) and sodium tripolyphosphate (STPP) addition on the quality of instant noodles from sweet potato starch. The diversification of raw material used in noodle production often necessitates processing modifications. Heat-moisture treatment was applied to native sweet potato starch (HMTSPS) in three conditions $\left(110^{\circ} \mathrm{C} ; 10,20\right.$ and $\left.30 \mathrm{~min}\right)$ and STPP was added in three level $(0,60 ; 0,75$ and $0,90 \%)$. HMTSPS, STPP, water, lecitin and CMC were mixed. The mixture was pelleted, steamed and extruded. The extruded noodles were dried using a microwave oven. The noodles were evaluated both when dry and after cooking. The HMT method and STPP addition improved noodle quality. Swelling index, solid loss and cooking loss of the noodles was decreased, while the texture and the elastisity of the noodles was higher. But noodles made with added of STTP more than $0,75 \%$ had low elastisity. The best instant noodle prepared by HMT method for 20 min and added of STTP $\mathbf{0 , 7 5 \%}$.
\end{abstract}

Key words: Sweet potato starch, heat-moisture treatment, STPP

Diterima: 26 Mei 2005, disetujui: 27 Januari 2006

\section{Pendahuluan}

Dalam rangka mewujudkan ketahanan pangan di Indonesia, salah satu strategi yang digunakan adalah pengembangan keragaman pangan. Diantara pangan sumber karbohidrat yang mempunyai potensi besar untuk dikembangkan adalah umbi-umbian diantaranya adalah ubi jalar. Selama ini ubi jalar dikembangkan menjadi tepung ubi jalar, pati ubi jalar dan alkohol (Suryatna, 1982). Di Cina sudah lama dikenal sohun dari ubi jalar (Huang, 1996). Diduga pati ubi jalar juga dapat digunakan sebagai bahan mi instan. Mi instan merupakan makanan populer di Indonesia, bahkan menjadi makanan pokok alternatif (Anonim, 2001). Mi instan adalah mi yang biasanya memerlukan pemasakan dalam air mendidih selama 3-4 menit sebelum disajikan (Kim, 1996). Menurut Standar Industri Indonesia nomor 0716-1990 mi instan siap dihidangkan setelah dimasak atau diseduh dengan air mendidih paling lama 4 menit (Anonim, 1990). Noodle adalah istilah umum untuk olahan pangan yang banyak mengandung pati berbentuk benang-benang. Noodle dapat dimasukkan ke dalam kelompok pasta (Marconi \& Carsea, 2001). Noodle dapat dibuat dari tepung padi-padian seperti gandum, beras, jagung, sorgum dan otek dan dari pati-patian seperti kacang hijau dan juga dari rumput laut (Huang, 1996).

Ubi jalar segar mengandung 15-40\% bahan kering yang sebagian besar (75-90\%) terdiri dari karbohidrat yaitu pati, selulosa, hemiselulosa dan pektin (Collin \& Walter, 
1985). Kadar pati ubi jalar putih adalah 79,63\% bk (Lingga, 1986). Kadar amilosa pati ubi jalar adalah 29,48\% bk (Suryani, 2001). Jika pati ubi jalar tersebut digunakan sebagai bahan baku pembuatan mi instan diduga akan diperoleh mi dengan kualitas yang kurang baik. Hal ini sesuai dengan hasil penelitian sebelumnya yang menyatakan bahwa sohun dari pati ubi jalar bermutu kurang baik karena kadar amilosanya relatif rendah sehingga retrogradasi pati sangat kurang (Suryani, 2001). Hal ini menyebabkan selama proses pemasakan mi banyak kehilangan padatan dan tekturnya kurang kokoh. Bahan mi yang ideal adalah terigu. Hal ini karena dengan penambahan air dan perlakuan mekanis gluten akan membentuk struktur jaringan tiga dimensi yang dapat memerangkap pati sehingga tidak terjadi leaching pati dan mempunyai tekstur yang elastis dan lenting.

Collado et al., (2001) menyatakan bahwa perlakuan pemanasan pati ubi jalar pada kadar air rendah (HMT) akan meningkatkan jumlah ikatan antar amilosa sehingga dapat memperkokoh tekstur bihun yang dihasilkan. Miyoshi (2002) menyatakan bahwa makin tinggi derajat HMT, makin tinggi kadar amilosa pati. Amilosa baru terbentuk dari cabang linier terluar amilopektin yang terdegradasi oleh perlakuan tersebut sehingga HMT dapat meningkatkan retrogradasi gel pati. Oleh karena itu diduga proses pemanasan pada kadar air rendah dapat meningkatkan kualitas mi dari ubi jalar.

Selain itu Marconi dan Carsea (2001) menyatakan bahwa untuk membuat produk pasta seperti mi dari bahan non terigu perlu pengembangan formulasi antara lain penggunaan bahan tambahan seperti mono atau digliserida serta pengental seperti polifosfat. Polifosfat meningkatkan gelatinisasi pati dan dapat mengurangi susut masak. Salah satu jenis pengental adalah sodium tripoli fosfat (STPP).

Tujuan penelitian ini adalah mengetahui pengaruh lama perlakuan HMT dan penambahan STPP terhadap kualitas mi instan dari pati ubi jalar yang dihasilkan serta menentukan lama HMT dan penambahan STPP yang tepat sehingga diperoleh mi instan yang mempunyai kualitas yang baik.

\section{Metode Penelitian}

\section{Bahan dan alat}

Bahan yang digunakan dalam penelitian ini adalah ubi jalar varietas ciceh yang diperoleh dari pasar umbi-umbian Yogyakarta. Natrium tripolifosfat, CMC (teknis) dan bahan kimia lainnya untuk analisa kimia. Alat yang digunakan antara lain adalah microwave oven, peralatan ekstraksi pati, oven pemanggang, pengering kabinet, alat pencetak $\mathrm{mi}$ dan seperangkat alat gelas untuk analisa kimia.

\section{Ekstraksi pati ubi jalar}

Ekstraksi pati menggunakan metode Utomo dan Antarlina (1997) yang dimodikasi dengan penambahan $\mathrm{Na} \mathrm{HSO}_{3}$ teknis selama perendaman bubur ubi jalar. Tahap-tahap ekstraksi pati meliputi pemarutan, perendaman dalam larutan $\mathrm{Na}^{\mathrm{HSO}_{3}} 300$ ppm (1:3 b/v), penyaringan dan pencucian sampai pati bersih sebanyak tiga kali, kemudian pati basah dikeringkan dengan pengering kabinet selama delapan jam pada suhu $50^{\circ} \mathrm{C}$. Pati kering sebelum digunakan dihaluskan dan diayak (60 mesh).

\section{Pembuatan Mi Instan}

Pati ubi jalar sebelum digunakan untuk membuat mi, pertama kali diberi perlakuan HMT. Pati ubi jalar kering ditambah air hingga kadar airnya sekitar 30\%. Setelah itu dipanggang pada suhu $110^{\circ} \mathrm{C}$ dengan variasi lama waktu 10, 20 dan 30 menit, pati ubi jalar hasil perlakuan HMT digunakan sebagai bahan baku pembuatan mi instan.

Pembuatan mi instan menganut metode Suhendro dkk. (2000) dengan modifikasi. Tahap-tahap pembuatan mi instan adalah pati HMTSPS dicampur dengan STPP dengan variasi penambahan 0,$60 ; 0,75$ dan $0,90 \%$, lesitin 3\%, CMC 1,5\% dan air $70 \mathrm{ml}$ untuk setiap $100 \mathrm{~g}$ pati HMTSPS, adonan homogen kemudian dibentuk pelet dengan alat penggiling dan dikukus selama 1 menit dan secepatnya dicetak, pilinan mi yang diperolah kemudian dikukus hingga matang (10 menit). Mi mentah yang diperoleh dikeringanginkan dan dimasak dengan microwave oven (5 
menit). Mi instan yang diperoleh disimpan dalam plastik kedap uap air sebelum dianalisa.

\section{Analisa bahan dasar dan mi instan}

Bahan dasar dianalisa kadar air (Metode AOAC (1970) dalam Sudarmadji et al., (1984), pati (Metode hidrolisis asam dalam Sudarmadji et al., (1984) dan kadar amilosa (Metode IRRI (1971) dalam Apriyantono et al., (1989)). Mi instan yang diperoleh dianalisa tekstur dan tingkat elastisitas mi seduhannya dengan alat Lloyd Universal Testing Machine.

Pengukuran swelling Index, solid loss dan total cooking loss dengan metode Mestress et al., (1988). Air bersih dipanaskan dalam beaker glass $250 \mathrm{ml}$. Setelah mendidih $5 \mathrm{~g} \mathrm{mi}$ terpotong-potong $2 \mathrm{~cm}$ dimasukkan, dimasak selama waktu pemasakan optimal dan pemasakan dilanjutkan 1 menit lebih lama. Sampel kemudian ditiriskan selama 5 menit dan cepat ditimbang (W1). Mi hasil masakan selanjutnya dikeringkan dalam oven pada $130^{\circ} \mathrm{C}$ sampai mencapai berat konstan (W2). Air hasil masakan disentrifugasi (7500 rpm) selama 10 menit, kemudian berat kering dari sedimen (W3) dan supernatan (W4) ditimbang. Jika DM adalah berat kering sampel maka swelling Index, solid loss dan total cooking loss dengan swelling Index, solid loss dan total cooking loss dihitung dengan rumus sebagai berikut:

$$
\begin{aligned}
& \text { Swelling Index }(\mathrm{SI} \%)=(\mathrm{W} 1-\mathrm{W} 2) \mathrm{X} \text { 100/W2 } \\
& \text { Solid loss }(\mathrm{SL} \%)=\mathrm{W} 3 \text { X 100/5 X DM } \\
& \text { Total cooking loss }(\mathrm{TCL} \%)=(5 \mathrm{X} \mathrm{DM}-\mathrm{W} 2) \\
& \text { X 100/(5XDM) }
\end{aligned}
$$

Waktu pemasakan optimal ditentukan dengan metode AACC (1995) dalam Collado et al., (2001). Mi sebanyak 5 g dipotong-potong sepanjang $5 \mathrm{~cm}$ dan dimasak dalam $200 \mathrm{ml}$ air mendidih dalam beaker glass yang tertutup. Selama pemasakan untaian mi diambil dari air dengan interval 30 detik dan dipres diantara dua kaca sehingga terlihat kematangan mi. Mi telah matang jika bagian tengah mi telah transparan atau seluruh mi telah terhidrasi. Hasil uji waktu pemasakan optimal berkisar antara 3,0-4,0 menit.
Data yang diperoleh kemudian dianalisa varian. Bila terdapat pengaruh yang nyata dilanjutkan dengan DMRT pada tingkat signifikansi $5 \%$.

\section{Hasil dan Pembahasan}

\section{Bahan dasar}

Bahan dasar yang digunakan adalah pati hasil ekstraksi dari ubijalar varietas ciceh. Pati hasil ekstraksi berwarna putih dan mempunyai kadar air $12,95 \%$ bb dan kadar pati $93,83 \%$ bk. Sedangkan kadar amilosa pati ubijalar yang digunakan dalam penelitian ini adalah 29,47\% bk. Berdasarkan kadar amilosanya maka pati ubijalar yang digunakan dalam penelitian ini dikategorikan sebagai pati berkadar amilosa sedang sehingga jika digunakan sebagai bahan baku mi diduga mi yang dihasilkan mempunyai kualitas hasil masakan kurang baik.

\section{Kualitas mi}

\section{Indeks pengembangan}

Indeks pengembangan menunjukkan kemampuan menyerap air kembali selama pemasakan mi. Hasil analisa statistik menunjukkan bahwa variasi penambahan STPP dan variasi lama perlakuan HMT berpengaruh nyata terhadap indeks pengembangan mi instan yang dihasilkan, sedangkan interaksi antara variasi penambahan STPP dan variasi lama perlakuan HMT tidak berpengaruh nyata $(\mathrm{P}=0,05)$. Makin lama perlakuan HMT maka indeks pengembangan makin kecil (Gambar 1). Hal ini karena makin lama perlakuan HMT jumlah ikatan antar amilosa makin besar (Collado et al., 2001) sehingga integritas granula pati makin kuat dan kemampuan memerangkap air juga makin kecil.

Makin besar penambahan STPP, makin kecil indeks pengembangan. Hal ini karena makin besar penambahan STPP maka makin banyak terbentuk ikatan silang antarmolekul pati dengan gugus fosfat. Wurzburg (1977) menyatakan bahwa keberadaan ikatan silang dengan gugus fosfat tersebut dapat meningkatkan struktur jaringan internal granula pati sehingga tidak mudah pecah. 


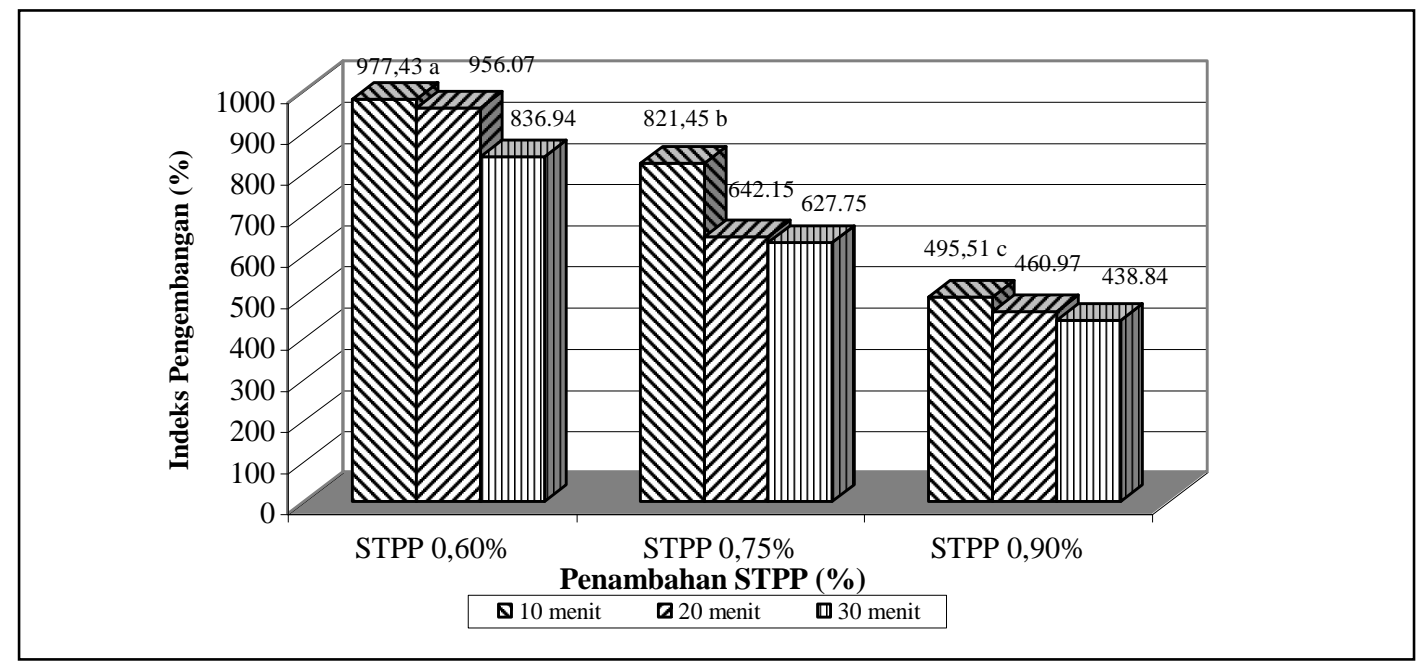

Gambar 1. Indek Pengembangan mi instan dari pati ubijalar (\%)

\section{Kehilangan padatan}

Hasil analisa statistik menunjukkan bahwa interaksi antara variasi lama perlakuan HMT dan variasi penambahan STPP berpengaruh nyata terhadap tingkat kehilangan padatan mi selama dimasak $(\mathrm{P}=0,05)$. Makin lama perlakuan HMT dan makin besar penambahan STPP, tingkat kehilangan padatan makin kecil (Gambar 2). Hal ini karena makin lama perlakuan HMT maka ikatan antar amilosa makin besar sehingga granula pati makin kokoh sehingga tidak mudah hancur selama pemasakan.

Makin besar penambahan STPP ikatan silang antar molekul pati makin banyak sehingga integritas granula pati juga makin besar. Granula berikatan silang tidak mudah putus dan lebih tahan terhadap pemecahan oleh pengadukan dan suhu tinggi (Ruttenberg \& Solarek, 1984; Whisler \& Daniel, 1985), sehingga mi instan selama direbus tidak mudah rusak dan tingkat kehilangan padatan makin kecil.

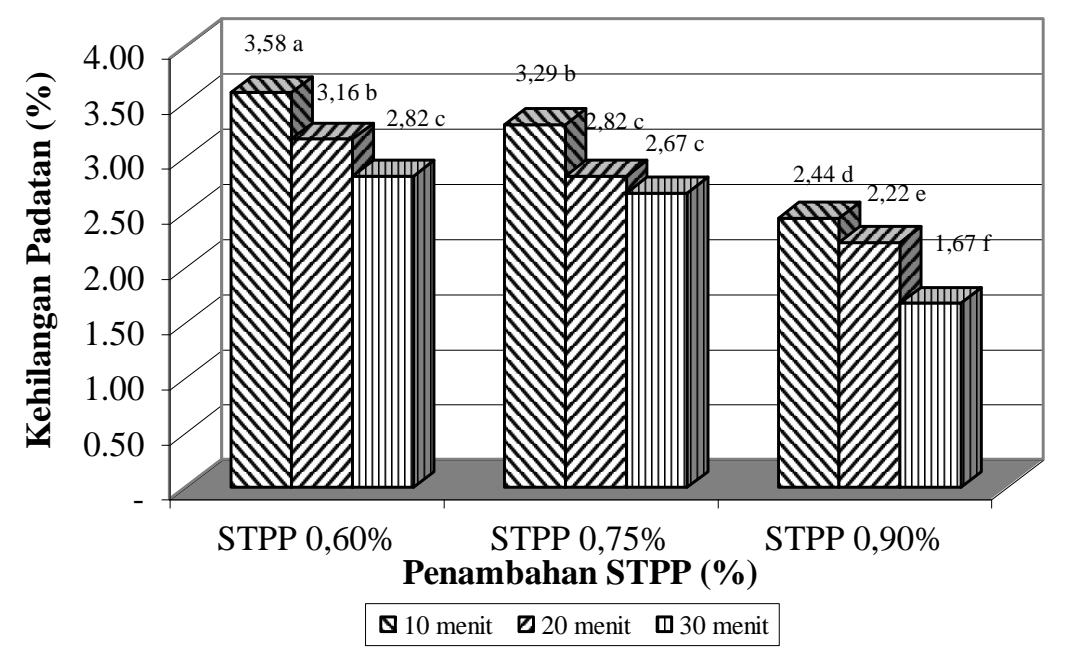

Gambar 2. Kehilangan padatan selama pemasakan mi instan dari pati ubijalar (\%). 


\section{Susut masak total}

Susut masak total selama pemasakan menunjukkan tingkat kualitas mi yang berhubungan dengan ketahanan mi terhadap proses disintegrasi selama pemasakan (Galvez et al., 1994). Kehilangan padatan selama pemasakan terjadi kerena bahan yang terpecah dan terikut atau larut dalam air rebusan. Hasil analisa statistik menunjukkan bahwa interaksi antara variasi lama perlakuan HMT dan penambahan STPP berpengaruh nyata terhadap susut masak total mi yang dihasilkan $(\mathrm{P}=0,05)$.
Makin lama perlakuan HMT dan makin besar penambahan STPP maka susut masak total makin kecil (Gambar 3). Hal ini karena makin lama perlakuan HMT maka ikatan antar amilosa makin besar sehingga granula pati makin kokoh sehingga tidak mudah larut. Makin besar penambahan STPP ikatan silang antar molekul pati makin banyak sehingga integritas granula pati juga makin besar. Hal ini menyebabkan mi instan selama direbus tidak mudah rusak dan amilosa tidak mudah larut sehingga susut masak total makin kecil.

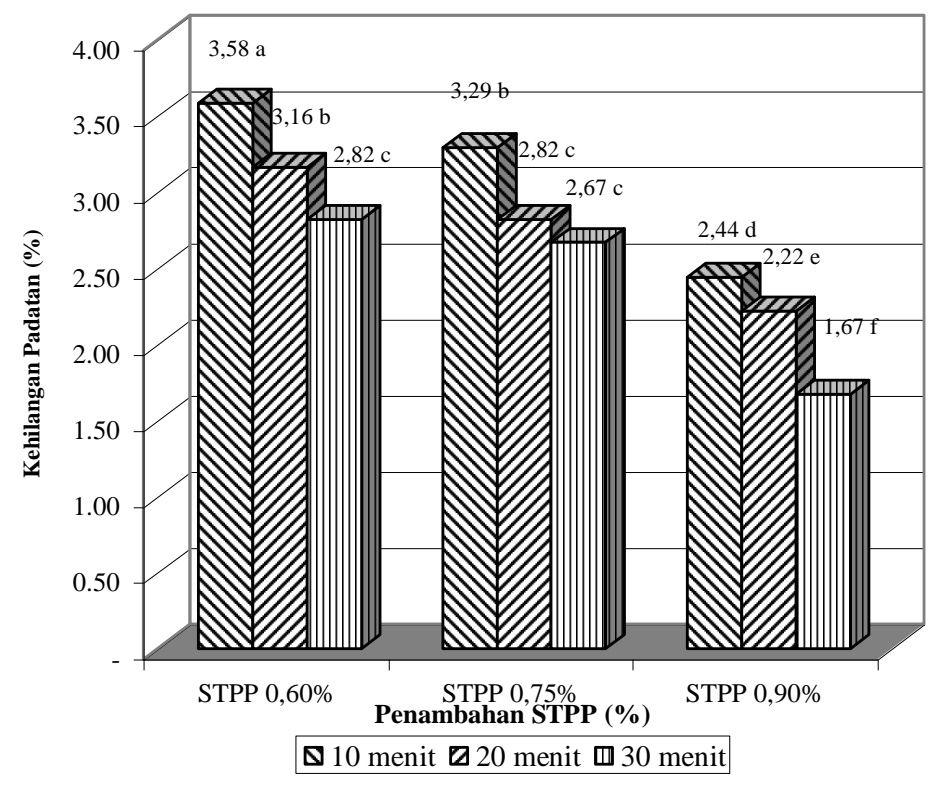

Gambar 3. Total susut masak mi instan yang dibuat dari pati ubijalar

\section{Tekstur}

Tekstur yang diukur menunjukkan tingkat kekerasan mi instan setelah dimasak. Hasil analisa statistik menunjukkan bahwa interaksi antara variasi lama perlakuan HMT dan variasi penembahan STPP berpengaruh nyata terhadap tingkat kekerasan mi yang telah dimasak $(\mathrm{P}=0,05)$. Makin lama perlakuan HMT, makin besar tingkat kekerasan mi masak (Gambar 4). Hal ini karena makin lama perlakuan HMT, makin banyak terjadi ikatan antar molekul amilosa, sehingga granula pati makin kokoh sehingga mi masak lebih keras. Kondisi tersebut sesuai dengan indeks pengembangan mi masak yang juga rendah (Gambar 1).

Makin banyak penambahan STPP maka tingkat kekerasan mi masak juga makin besar. Hal ini karena makin banyak STPP yang ditambahkan maka makin banyak ikatan silang antar molekul pati oleh gugus fosfat sehingga integritas granula pati tinggi dan retrogradasi makin tinggi sehingga selama pemasakan tekstur mi tetap kokoh. 


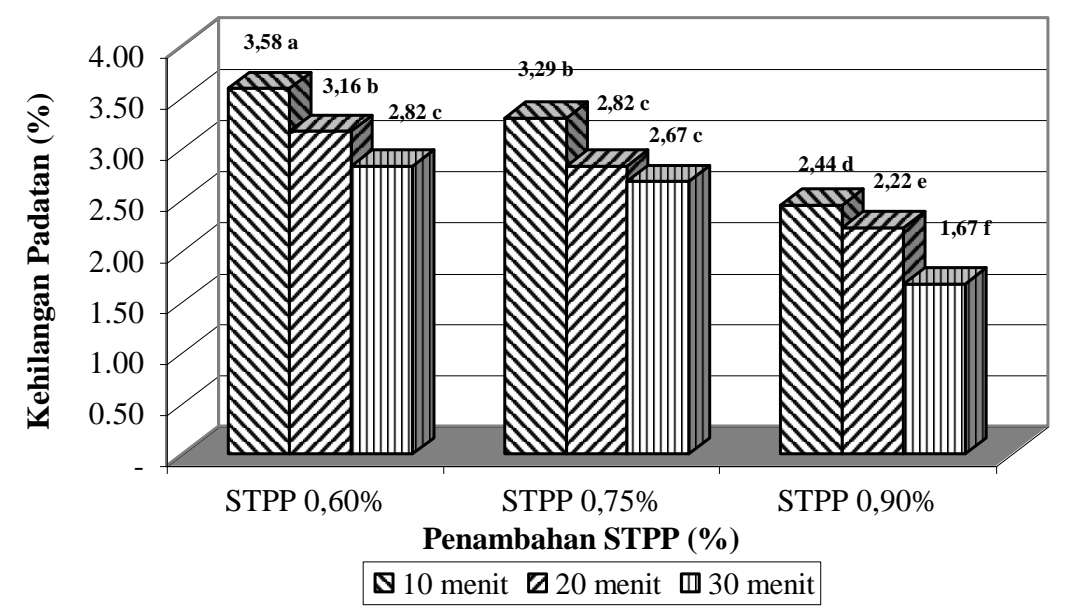

Gambar 4. Tekstur mi instan dari pati ubijalar setelah pemasakan (N)

\section{Tingkat deformasi elastis}

Tingkat deformasi menunjukkan tingkat kekenyalan mi yang telah dimasak. Makin besar tingkat deformasi elastisnya menunjukkan mi makin kenyal. Hasil analisa statistik menunjukkan interaksi lama waktu perlakuan HMT dengan variasi penambahan STPP berpengaruh nyata terhadap tingkat elastisitas mi masak yang dihasilkan $(\mathrm{P}=0,05)$. Makin lama perlakuan HMT, makin besar deformasi elastis mi, berarti mi yang dihasilkan makin kenyal (Gambar 5). Jika lama perlakuan HMT lebih dari 20 menit berakibat tingkat deformasinya menurun. Hal ini karena pada perlakuan HMT lebih dari 20 menit, jumlah ikatan antar molekul amilosa sangat banyak hingga tingkat kekerasan mi sangat tinggi, menyebabkan deformasi elastis rendah. Makin banyak penambahan STPP, makin besar deformasi elastisnya, tetapi jika penambahannya lebih dari $0,75 \%$ akan menurunkan deformasi elastisnya. Pada penambahan STPP lebih dari $0,75 \%$ terbentuk ikatan silang antarmolekul pati oleh gugus fosfat yang lebih banyak. Hal ini mengakibatkan granula pati menjadi sangat kompak dan indek pengembangannya rendah (Yook et al., 1993).

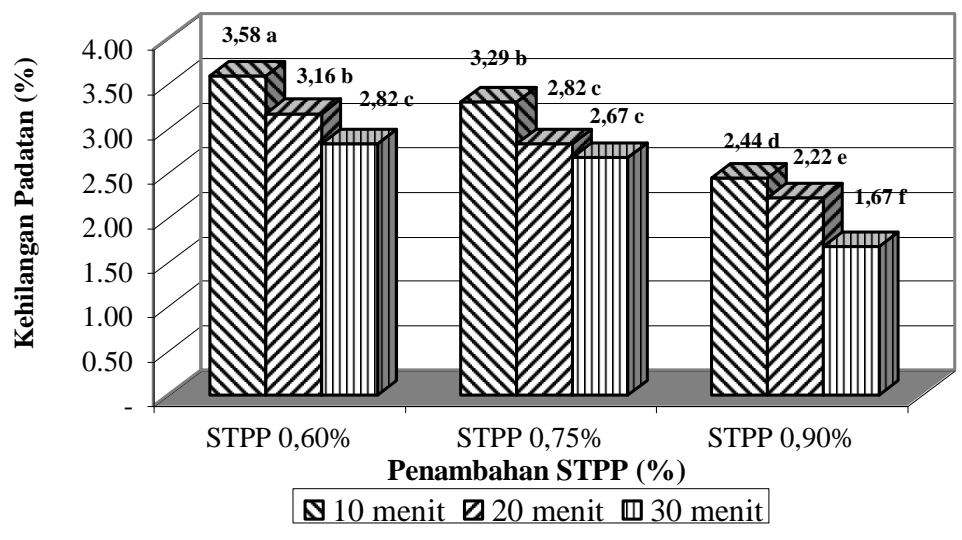

Gambar 5. Tingkat deformasi elastis mi instan dari pati ubijalar (\%) 


\section{Kesimpulan}

Berdasarkan hasil penelitian dapat disimpulkan bahwa pati ubijalar dapat digunakan sebagai bahan baku mi instan. Makin lama perlakuan HMT maka indeks pengembangan, tingkat kehilangan padatan dan susut masak total makin kecil, sedang tekstur dan deformasinya makin besar, namun sebaliknya pada lama perlakuan HMT lebih dari 20 menit elastisitasnya makin kecil. Makin besar penambahan STPP maka indeks pengembangan, tingkat kehilangan padatan dan susut masak total makin kecil, sedang tekstur dan deformasinya makin besar, namun pada penambahan STPP lebih dari 0,75\% deformasinya makin kecil. Mi instan yang terbaik adalah yang dibuat dengan lama perlakuan HMT 20 menit dan penambahan STPP sebanyak $0,75 \%$. Berdasarkan pengamatan visual diketahui bahwa mi yang dihasilkan masih mempunyai kelemahan yaitu sifat ekstensibilitas yang relatif kecil sehingga perlu dikaji lebih lanjut.

\section{Ucapan Terima Kasih}

Penulis mengucapkan terima kasih kepada Pimpinan Proyek Peningkatan Penelitian Perguruan Tinggi atas ijin dan dana untuk penelitian ini melalui program dana penelitian Dosen Muda. Kepada saudara Zarfanah dan Ika Rini, terima kasih atas bantuan teknis penelitian ini.

\section{Daftar Pustaka}

Anonim. 2001. Mie Instan Makanan Pokok Alternatif yang Terbaik? F\&B Bulletin Food and Beverage Industry 2: 5-8.

Apriyantono, A., Fardiaz, D., Puspitasari, N.L., Sedarnawati dan Budiyanto, S. 1989. Petunjuk Laboratorium Analisis Pangan. PAU Pangan dan Gizi, Institut Pertanian Bogor.

Collado, L.S., Mabesa, L.B., Oates, C.G. and Corke, H. 2001. Bihon-Type Noodles from HeatMoisture Treated Sweet Potato Starch. Cereal Chem. 66(4): 604-609.
Collin, W.W. and Walter. 1985. Fresh Roots for Human Consumtion. In: JC Boukamp. (Eds.). Sweet Potato Product, a Natural Resource for the Tropic. CRC Press Inc Bocaraton, Florida.

Galvez, F. C. F., Resurreccion, A.V.A. and Ware, G.O., 1994. Process Variables, Gelatinized Starch and Moisture Effect on Physical Properties of Mungbean Noodles. J Food Sci. 59(2): 370386.

Huang, S. 1996. A look at noodles in China. Cereal Food World. 41(40): 199-204.

Kim, S.R., 1996. Instan Noodle. In : J.E. Kruger, R.B. Matsuo and J.W. Dick. (Eds.). Pasta and Noodle Technology. American Association of Cereal Chemists, Inc. Minnesota. USA.

Lii, C.Y. and Chang, S.M. 1986. The Properties Of Some Modified Starches and Their Applications. In : O. R. Fennema, W.H. Chang and C.Y.Lii. (Eds.). Role of Chemistry in The Quality of processed Food. Food and Nutrition Press, Inc. Connecticut. USA

Lingga, P. 1986. Budidaya Ubi-ubian. Penebar Swadaya, Jakarta.

Marconi, E. and Carsea, M. 2001. Pasta from Nontraditional Raw Material. Cereal Chem 46(11): 522-530.

Mestres, C., Colona, P. and Buleon, A. 1988. Characteristics of Starch Networks Within Rice Flour Noodles and Mungbean Starch Vermicelli. J Food Sci. 53 (6): 1809-1812.

Miyoshi, E. 2002. Effect of Heat-Moisture Treatment and Lipids on Gelatinization and Retrogradation of Maize and Potato Starches. Cereal Chem 79(1): 72-77.

Ruttenberg, M.W. and Solarek, D. 1984. Starch Derivatives, Production and Uses. In: R.L.Whistler, J.N.Be Miller and E.F.Paschall. (Eds.). Academic Press, Inc. Orlando.

Sudarmadji, S., Haryono, B. dan Suhardi. 1984. Prosedur Analisa Bahan Makanan. Liberty, Yogyakarta.

Suhendro, E.L., Kunetz, C.F., Mc Donough, C.M., Rooney, L.W. and Waniska, R.D. 2000. Cooking characteristic and Quality of Noodle from Food Sorghum. Cereal Chem. 77(2): 96-100.

Suryani, Ch. L. 2001. Kajian Penggunaan Pati Komposit Sebagai Alternatif Bahan Baku Pembuatan Sohun. Laporan Penelitian. Universitas Wangsa Manggala. Yogyakarta.

Suryatna. 1982. Ubijalar dan Kemungkinan Perkembangannya di Indonesia. Institut Pertanian Bogor, Bogor. 
Utomo, J.S. dan Antarlina, S.A. 1997. Kajian Sifat Fisik Kimia Pati Umbi-Umbian Lain Selain Ubi Kayu. Prosiding Seminar Nasional Teknologi Pangan, PATPI dan Kantor Menteri Negara Urusan Pangan. Denpasar Bali.

Whistler, R.L. and Daniel, J.R. 1985. Carbohydrates. In: Fennema, O.R. (Eds.). Food Chemistry. Marcel Dekker, Inc. New York.

Wurzburg, O. B., 1977. Starch In The Food Industry. In: Furia, T.E. (Eds.). Handbook of Food Additives. Chemical Rubber Co. Boca Raton.

Yook, A., Pek, U.H. and Park, K.H. 1993. Gelatinization and Retrogradation Characteristic of Hydroxypropylated and Cross Linked Rices. J. Food Sci 58(2): 405-407. 